\title{
How do we safeguard and improve the healthcare workforce for doctors? Society for Healthcare Reform, 2 March 2020
}

\section{Colin Elton*}

Royal Free London NHS Foundations Trust, London, UK

${ }^{*}$ Corresponding author at: Barnet Hospital, Wellhouse Lane, Department of General Surgery, Barnet, EN5 3DJ, UK.

Email: info@colinelton.com

Date accepted for publication: 3 June 2020

\section{Abstract}

An expert panel, leading doctors, trainees and medical students from the UK National Health Service (NHS) were invited to take part in an open debate covering a range of issues, with an aim of recommending changes to safeguard and improve the healthcare workforce. The debate focused on areas to consider for potential reform within the NHS workforce, undergraduate medical education, the junior doctors and the consultant workforce. There was a detailed interactive discussion and various recommendations were made.

Keywords: healthcare workforce; medical education; junior doctors; consultants

\section{Introduction}

An expert panel, leading doctors, trainees and medical students from the UK National Health Service (NHS) were invited to take part in this open debate covering a range of issues, with an aim of recommending changes to safeguard and improve the healthcare workforce. It is intended that more debates will follow in due course, covering other topics that raise flags.

\section{Chair}

Colin Elton (Consultant Colorectal Surgeon)

\section{Expert Panel}

Professor Derek Alderson (President Royal College of Surgeons)

Dr Katherine Henderson (President Royal College of Emergency Medicine)

Professor Mayur Lakhani (Past President Royal College of General Practitioners)

Dr Ben Mearns (Chief of Medicine, Surrey and Sussex Healthcare NHS Trust)

Dr Clare Stephens (GP Barnet CCG, Clinical SRO NCL Cancer Programme)

Dr Nick Dattani (GP Clinical Lead Barnet CCG)
Dr Vishal Sharma (Cardiologist and BMA Pensions Committee Chair)

Mr Ray Stanbridge (Accountants and Tax Advice for Medical Accountants)

Dr Alka Patel (Lifestyle and Medicine Physician)

Ms Tara Kent (CEO of Champs, Positive Wellbeing at Work)

Ms Megan Annetts (President Barts and The London Students' Association)

The discussions taking place at this meeting included:

(1) NHS workforce - areas to consider for potential reform

(2) Medical school - undergraduate medical education

(3) Junior doctors

(4) Consultants

\section{NHS workforce: areas to consider for potential reform}

\section{Opening discussion by Chair}

The NHS is the fifth largest employer in the world with 1.7 million employees (1.4 million employees in 2010). One 
million patients are seen every 36 hours; 150,000 doctors are working in the NHS, through hospital, community and primary care. In 2018, there were 290,000 doctors registered in the UK (9000 registered aged over 70 years). The headcount of hospital medical staff grew from 87,000 in 2004 to more than 120,000 in July 2019 - a $38 \%$ increase. The number of hospital consultants increased by $67 \%$ (from 30,650 to 51,250). In 2016/2017, the total cost of NHS staff was $£ 47.6$ billion, $44.9 \%$ of the NHS budget.

Problems identified:

- The UK lost 441 general practitioners (GPs) last year and there were 11,576 unfilled vacancies for doctors as of June 2019

- Workforce numbers are not keeping pace with increasing workload

- Low morale

- Increased levels of stress and feelings of 'not being valued'

- Bullying and harassment

- Pensions crisis

\section{Summaries from Expert Panel}

Derek Alderson: There is a difficulty in recruiting. Fewer people are interested and there is less competition into surgical training. There is a feeling of dissatisfaction. Young surgeons' training skills are not recognized and they feel less appreciated. We need to attract people to enter the job, to enjoy and feel valued within the industry.

Katherine Henderson: In emergency medicine, we have doctors with the qualifications. There is not a recruitment problem, but a problem with retaining them. We are good at training our doctors, but when they go abroad for work and experience, they decide not to return. We need to hold onto our doctors and nurses. We also need to encourage multidisciplinary teams and team working. There is a strong need to provide a stable workforce to deliver good care and this stems from good organized training.

Mayur Lakhani: There is a very serious problem of unhappy doctors worldwide, being overworked. We are short on solutions. Doctors are driving for change to give the excellent care they have been trained to do. There is too much of a divide between professions. We require an $\mathrm{ABC}$ of Autonomy (America design job plan) to have some control on workload. We cannot have over 100 patients for one doctor. Doctors are being overworked and with no sense of belonging. Competence and clinical excellence make the profession. I would suggest: 'Free parking for all doctors, $£ 280$ a month for car parking, a laptop for each doctor.' Having to share one computer that barely works results in daily struggles. This leads to twice as much time on administration and system problems. We need a clinically led model in primary care. I feel that we should have a medically led NHS, and we should have clinical roles running hospitals.

Ben Mearns: There is $13 \%$ more emergency work compared with last year. The complexity is high, with more complex cases. We need more capable doctors and to have increased clinical capacity. We need diverse teams, having the right skills. What is very important is to widen the target for recruitment. We need to ask: 'Which clinician can do what for each patient?' Happiness is important, a sense of being valued. We need to be as one team looking after the staff and the patient. The happier the staff are, the better the care. We need to show students and young doctors that they can have a happy career.

Clare Stephens: Medicine risks losing its position as a highvalued profession. The way the UK has chosen to apply the European Working Time Directive for our medical staff has profoundly affected how our trainees experience training and ultimately how we deliver clinical care. Junior doctors reflect to us how their hospital experience makes them feel undervalued. They speak of a lack of clinical continuity. This translates into poorer patient experience and affects the levels of faith and trust the public place in our health service. We need experienced clinical leaders throughout the NHS, and these clinical leaders should ensure they continue to practice at the coal face as part of established teams. Effective leaders need to guard against minimalist token practice and instead lead from the front line.

Nick Dattani: Our GP workload has increased substantially. We can receive discharge summaries from 17 doctors. We commonly work 5 days a week, resulting in over 60 hours a week. It is not sustainable to work that many hours. As a result, GP morale is very low. There is not enough investment going into primary care NHS. Problems are always thrown back at the GPs. We need to consider sharing the healthcare budget between primary and secondary care. We need to invest more in training, rather than just working to registration. We are investing in paramedics as GPs, but there needs to be financial support for a better budget.

Vishal Sharma: In the last 20 years of the NHS, this is now the worst morale amongst doctors. Although the headcount is increasing, the capacity has gone down. People are doing less work. The issue of pensions has contributed to the crisis. 140,000 registered doctors are not working in the 
NHS although there are a small number of doctors over the age of 70 years. Doctors in their late 50s would like to work but have been forced out to retire due to poor working conditions and pension changes.

Ray Stanbridge: Due to the current pensions changes, there are the following consequences:

- Retrospective information creating uncertainty and difficulty for individuals

- Reluctance of consultants to take on new sessions

- Reluctance of consultants to take on promotions/merit awards

- Growth in numbers 'opting out' of pensions

- Consultants switching to private sector

- Growth in trading through limited liability companies

- Increasing numbers going part-time in the NHS

Other difficulties include: shortness of supply of doctors in the system; doctors are under more stress; there are failed IT systems and not enough investment in improving care; doctors are unable to whistle blow; they are worried about management and the future of their careers.

Alka Patel: We are negligent doctors if we neglect ourselves. We should focus on self-compassion, and widen the compassion to others (work colleagues and patients). We should be part of a team, within our trust and the NHS. We should aim to make a change in our own lifestyle. 1 in 3 of us will suffer burnout. We need to identify the triggers for stress and develop our interior to handle the exterior.

Tara Kent: We need to identify early warning signs, because burnout is a real risk. We need to support organizations to see what others do differently and learn from each other. Belonging and forms of support have gone astray. The healing profession should help and support you. We need to try and stop people from going on the wrong track.

Megan Annetts: Medical school admissions have increased. Students with increasingly better A-level results, $\mathrm{A}^{*} / \mathrm{A}$ grades, are signing up for medicine before they really know what it is. Students drop out when they realize this career is not for them. Students are overworked. They have exams, presentations, placements, etc. to develop resilience, but the work and pressure are pushing some students to braking point before they have even started their career. Commuting and financial pressures for students are significant, including the cost of exams and qualifications. In hospital, there is a loss of identity and team structure, which worries students.

\section{Medical school: undergraduate medical education}

\section{Background}

There are 33 medical schools in the UK (25 in England, 5 in Scotland, 2 in Wales, 1 in Northern Ireland). Five more medical schools have been announced, with 1500 more students by 2020 , an increase from 6000 to 7500 places. 23,710 students applied to study medicine for September 2020 (an increase of $6 \%$ compared with last year): 18,500 applicants from the UK (up 5\%), 1680 from the EU (up 1\%), 3530 from outside the EU (up 10\%). There are 11 or 12 applicants for each place. Medical school entry requirements are 3 A grades at A level plus UCAT (UK Clinical Aptitude Test) and BMAT (BioMedical Admissions Test). 205 UK schools are providing $80 \%$ of medical students.

An article in the BMJ in $2017^{1}$ looked at secondary schooling and subsequent medical school performance. The UCAT scores added value above and beyond secondary school achievement. Findings suggest that academic entry criteria should be relaxed for candidates applying from the least well-performing secondary schools. In the UK, this would translate into a decrease of approximately 1-2 A-level grades. Some medical schools offer grade discounts to applicants from less well-performing schools.

Research from the Royal Medical Benevolent Fund ${ }^{2}$ found that $60 \%$ of medical students have experienced financial pressures and $70 \%$ have experienced mental health pressures.

More than 1000 medical students have withdrawn from their course in the last 5 years (November 2018 data). 300 of the UK's 6000 medical students quit each year (5\%). Another 1600 are asked to leave for poor academic performance. There is a total loss of $32 \%$ of students.

\section{Current problems identified in MBBS medical education}

(1) Financial pressures

(2) Mental health issues

(3) University dropouts

What are the challenges surrounding medical school?

\section{Megan Annetts:}

- Workload for student: assessments, exams, tests, placements, requirements

- Receiving the wrong type of hospital teaching: standing and observing 
- Grade requirements are increasing

- Only those who are academically good, rather than those who excel at extracurricular activities

- Mental pressures: stigma at medical schools, high pressure before you are even a doctor

- Financial pressures, with no income; travel fares, e.g. Transport for London, while on placement

- Statistics show 5\% students quit, being unaware of what they are getting themselves into; at a young age to decide about one's career, there is such a large amount of debt

- There is a 50\% reliance on multiple choice questionnaires

Alka Patel: There is a struggle to have the correct training. We need to encourage good doctors, who are able to share their emotions, experiencing real life situations. Assessments do not reflect real life.

Clare Stephens: I would suggest bringing back Consultant Interview Appointment Panels. Steer away from IT-based selection processes which are too easy to 'game'. Medical students need to return to being considered truly part of the clinical team. A proportion of their day to day clinical training needs to happen delivering actual clinical care as part of a clinical 'firm structured' team. Clinical continuity is known to produce better health outcomes and students must be taught and shown this in their clinical practice experience.

Mayur Lakhani: Students need role models in medicine, showing passion and pride. Senior doctors should be encouraged to teach students. The current system grinds them down with the lack of value and support, so there is a constant pressure, which prevents the involvement of teaching. Students have a sense of confusion, frustration, uncertainty about their future. Working 6 years with exams of multiple choice in the final year (situation and judgement). Medical ethics are given a disproportionate importance in the final results. This then determines whether you can be an F1 doctor. Students feel that they have no control about where their first F1 job will be.

Daren Francis: Of great concern for those considering or embarking on medicine as a career are the large student debts, which can be $£ 100,000-£ 120,000$ by the end of medical school, with a starting salary of $£ 27 \mathrm{k}$. A huge decision and commitment for someone of such a young age. We need to make it more exciting; we have to tackle the debts and we have to engage with people.
Clare Stephens: Apprenticeship as an underlying premise of clinical training needs to return to the forefront of training. Active involvement and contribution from day to day patient care is necessary, to ensure students achieve competency and confidence. Encourage training systems that allow learning from mentorship.

Alka Patel: Technology has developed but we have not changed how we learn.

Clare Stephens: Final year students report huge anxiety about where they are going to be geographically and institutionally allocated. This needs to be changed. All of us, including new graduates have a right to exercise choice. Although it should not be mandated, it makes sense if appointments after qualifying as a new graduate stay in the area where the student has trained. They should be ranked within their local medical school. Current training is inflexible. Juniors report they do not know where they are going to be for their next job, and they have little influence. They feel their futures are being decided by others, by the system. The current situation is unfair and nonsensical. Trainees narratively report that this situation contributes to young doctors choosing to leave the profession. It is therefore not only ethically unfair, but ill-conceived and nonsensical from a national financial burden perspective. This is a bizarre state of affairs and is out of line with other professions.

\section{OUTCOME}

- We need to provide better financial support for students, e.g. similar to the grant provided by government for maths teachers. Consider free travel from Transport for London.

- We need to provide better welfare support within medical schools for mental health. We need to provide better training, particularly from senior doctors.

- We have to avoid an F1 placement lottery and plan jobs better.

- We should bring back student assistantships, paid jobs in last year of medical school to replace the F1.

- We need to attract students to careers and provide better career advice and nurturing. Apprenticeship needs to return to the forefront of training.

\section{Junior doctors}

According to a report from the General Medical Council in 2018 , there were 52,800 full-time equivalent hospital doctors 
in training, an increase of $2.4 \%$ (1250) since $2016 .{ }^{3}$ In 2017, $57.4 \%$ of Foundation Year 2 (FY2) doctors did not enter higher training posts and 9000 doctors quit the NHS entirely.

- 2011: 71.3\% of FY2 doctors progressed into higher training

- 2016: 50.4\% of FY2 doctors progressed into higher training

- 2018: 42.6\% of FY2 doctors progressed into higher training

Problems cited:

- Changes to doctors' salaries

- Hours worked

- Reduced investment in training

- Inflexibility with schedules

- Lack of consistent teamwork

- Understaffed service

- Lack of feeling valued and supported

- 3 of 10 doctors said they feel unsupported by management each week, and mentoring provided to them as part of their role has decreased.

The European Working Time Directive came into force in October 1998: a limit of an average of 48 hours worked each week. In August 2004, it was introduced for junior doctors, but only reached an average of 48 hours by August 2009 .

The NHS Long-Term Plan (published January 2019) The NHS Chief People Officer, ${ }^{4}$ working with the National Workforce Group will take action for all NHS staff to:

- improve health and wellbeing, building on the NHS Health and Wellbeing Framework, which includes recommendations from the Stevenson/Farmer review of mental health and employers, and to support improved health and wellbeing of staff and management of sickness absence

- support flexible working, including clarity on the proportion of roles to be advertised as flexible; and the ability to express preferences about shifts further in advance enabled by e-rostering technology introduced over the next year and associated applications

- clarify expectations on induction and other mandatory training
- enable staff to move from one NHS employer to another more easily

- set expectations for the practical help and support our staff should receive to raise concerns, or inappropriate behaviours, confidentially

Research by the Nuffield Trust ${ }^{5}$ found that the number of GPs per 100,000 people across the UK has reduced from a high of around 67 in 2009 to 60 in 2018. That is a similar number of GPs per person today as there was in 2004 . Based on data specifically from England, there has been an increase in part-time working. GPs were employed to work on average $82.1 \%$ of a full-time contract in September 2015, compared with 79.8\% in December 2018. This would be equivalent to around a 1,000 reduction in headcount across 42,000 GPs.

Across the UK, the number of GPs relative to the size of the population has reduced in a sustained way for the first time since the 1960s. The decrease in the number of GPs has been particularly marked in certain regions of England such as north-west London and east England. These regions have the lowest total number of GPs per 100,000 people, whereas Scotland has the highest. The decrease in GPs from 64.9 per 100,000 to 60 per 100,000 means the average doctor now has 125 more patients to look after than they did in 2014 .

The Nuffield Trust believes another 3500 GPs would be needed to get the NHS back to where it was in 2014 . There are just over 42,000 working currently, reduced by nearly 1500 in 4 years. The reduction in GPs reflects insufficient numbers previously being trained and going on to join the NHS; failure to recruit enough from abroad and more GPs leaving for early retirement.

Although training places are now being increased, in the region of one in three posts for specialty GP training do not result in a GP joining the NHS. More than 20,000 extra physiotherapists, clinical pharmacists, nurse practitioners, paramedics, physician associates and support workers are being recruited to help see GP patients in England. 5000 have been recruited in the last 3 years.

Is this now a time to change the culture from within the NHS? Working patterns, behaviour of colleagues towards each other and the way management interacts with the medical workforce?

Ben Mearns: At the end of the F2 year, we need to reach out to these doctors and do more. They need more education, and we could try to fill them within F3. We could manage these doctors correctly, as some end up wanting to do something completely different. 
Katherine Anderson: It is not just doctors; nursing staff are also under stressful conditions. They are not being given enough time to (i) do the job, (ii) do the training, (iii) think about it and develop. There should be an understanding within management that doctors need nurturing and are not just numbers to provide a service.

\section{Is it time to bring back the firm structure?}

Vishal Sharma: We should aim to work within a multidisciplinary team.

Derek Alderson: I agree that a multidisciplinary team structure works. We need alternative training pathways, nontraditional training. Structured training needs to be rethought. There are varied skill sets and we should adjust work according to these different skills.

Clare Stephens: Yes, it is time! Apprenticeship should be an underlying premise of clinical training. Belonging and being needed as part of the firm structure in day to day clinical care is paramount. Active involvement and contribution from day to day patient care is necessary to ensure students achieve competency and confidence. IT and bedside access to evidence-based medicine to support training in this context is important. We need more continuity of clinicians within clinical teams. This means more investment. Doctors need adequate desk space in hospital environments, and a re-provision of freshly prepared food in and out of hours for all staff.

Tara Kent: There are lots of different people within the system and there needs to be enabling of clinicians to ask others: how it is going? And for people to be heard and valued. This aspect is needed to help support systems with this industry.

Vishal Sharma: It is important to have a role model and to provide enough time for those doing the training. All grades of doctors should have a mentor. We should provide development on communication skills, simulation. There could be a replacement of elements of apprenticeships. We should aim for protected time for those who are training and help with all aspects, e.g. problems outside of work life. We should consider creating professional teachers during medical careers.

How do we direct medical students and junior doctors to fill the most severe workforce gaps?

Derek Alderson: Having the right workforce in the right place. Students could stay in the areas they enjoy most and have learnt about.

Bijen Patel: We offer an undergraduate MSc course to medical students with hands on practical training in surgery: suturing, bowel and vascular anastomoses. We get them at an early stage of learning, helping them with competencies and skills that can be transferred into the workplace and they absolutely enjoy it. We hope to extend this with gynaecology.

Mayur Lakhani: For GPs, there is an inability to control demand and the workload. There is an issue of quality of excellence and time to do their job.

Nick Dattani: For some GPs, there is not enough patient exposure. We need to encourage doctors to know that this is a flexible career. There needs to be more integration of GPs into hospitals. We should attract shared care, bringing morale back, and this helps to stop burnout.

Alka Patel: We need more GP fellowships to help people with handling the workload. The value of a GP should not be determined on having those 10 minutes with each patient.

Ben Mearns: We should aim to treat each other with respect. I don't think the system is treating students with respect: 'We value you, however you won't know where you are going to be working'.

Mayur Lakhani: We need physician leadership. We need to think about all other aspects, housing, depression, etc. Training and support is needed. For GPs, we should change the way they work, increasing the time with each patient.

\section{OUTCOME}

- We need to consider better planning for placements of medical students.

- We should have more GP fellowships.

- We should have mentors for doctors at every grade and consider appointing professional teachers. We could expand MSc degrees for undergraduates with practical skills that direct them to particular careers.

- At the end of the F2 year, we need to reach out to these doctors and, if necessary, we could try to place them within F3. We need to concentrate on supporting the junior doctor and letting them know that they are valued.

\section{Consultants}

Consultants have found their understanding of what a consultant is slowly eroded. This used to be the pinnacle of a hospital medical career and one to which we all aspire. However, things have changed. Loss of the secretary, loss of an office in many institutions, no protection from the busy workload as the service has become consultant delivered. Loss of the firm structure so there is no continuity of care with 
patients. Increasing computer/paperwork, service requirements, busy on calls, which means that a consultant is almost living in the Accident Emergency Department for the busy specialties: general medicine, general surgery, emergency medicine, obstetrics. Constant pressure and sometimes bullying and harassment from management whose style is often aggressive and disrespectful. Difficulty in providing the training to junior doctors. Complaints. And then there is the pensions crisis. I know several consultants who say: 'I come into the hospital every day, to my work, and then leave. Nothing more.' That is a sad state of affairs for such highly talented, previously motivated individuals.

Consultant numbers stood at 45,800 full-time equivalent, an increase of $3.4 \%$ (1490) since 2016. Latest figures show 49,068 consultants (published January 2020); this is the largest doctor workforce.

\section{How can we improve the culture towards consultants?}

Vishal Sharma: We should try to reduce the amount of administration and emails.

Alka Patel: Consultants are constantly giving back. We should give leadership to the consultants. They should be able to run the ward. Consultants should shape the working day for their teams.

Katherine Henderson: This does not reflect real life. This is not what happens in hospital. There should not be consultants deciding things; they have a job to do; we need to make sure people are doing the right job. Different hospitals practise differently. Professionalism is the most important thing and making sure we are doing things right.

\section{Protecting consultants}

- Professional development should happen throughout the career, 'what's next for myself?' We also need time for research.

- There needs to be more training in leadership. We are focused too much on our clinical job. There is limited time to develop skills. We need to have different things to maintain interest.

\section{Redesign job plans}

- When clinicians retire, how do we keep their talent within the NHS?

- Do we consider zero-hours contracts? Should we have more teaching and mentoring posts?

- We need to have flexible contracts for some senior clinicians, e.g. agreement by departments as to when to come off the on-call rota.
Vishal Sharma: Our partners are important, being told what you must be doing. The consultant career is about phases, different steps, e.g. 'Felt like he stopped and what does he do next?' People go through that and think, 'what can I do next?' Research can be managed between consulting teams, so new research is varied and covers different things for patient care.

\section{Pensions}

Vishal Sharma:

- Lifetime allowance tax charge 55\%

- Retire and then come back and do reduced sessions

- In the NHS Benefit schemes, you have no control how your pension grows

- There are high incomes towards the end of their career, especially with management roles

- Suddenly, $£ 10,000$ more tax becomes $£ 40,000$; to stop having such a high tax bill, consultants are reducing the work they are doing, which has an impact on the industry

- There is an announcement in the budget next week

- The threshold is likely to be raised to $£ 150,000$; there should not be an annual allowance

- These are not appropriate taxes that should be applied

\section{OUTCOME}

- Reduce administration and emails

- Protect consultants from bullying and harassment

- Redesign consultant job plans with flexible job plans: coming off on-call for senior doctors, zero-hours working, teaching and mentoring posts

- Empower consultants as leaders, provide leadership training

- Work to solve the pensions crisis as soon as possible

\section{Acknowledgements}

This meeting was sponsored by HCA Healthcare UK. The meeting was organised by $\mathrm{Mr}$ Colin Elton and Mr Neil Buckley (Vice-President, Physicians Services Group, HCA).

\section{Conflict of interest}

None declared. 


\section{References}

1. O'Dowd A. State educated children do better at medical school. BMJ 2017; 358: j4239. https://doi.org/10.1136/bmj. j4239.

2. Meredith J. Our medical student survey findings. Royal Medical Benevolent Fund. Nov 2018. Available from: https://rmbf.org/about/our-campaigns/medstudentsmatter/ourmedical-student-survey-findings/ (accessed 5 June 2020).
3. National Training Surveys 2018. General Medical Council, UK.

4. The NHS long-term plan: five things you need to know. The King's Fund; 2019. Available from: https://www.longtermplan. nhs.uk/ (accessed 5 June 2020).

5. Rosen R. Delivering general practice with too few GPs. London, Nuffield Trust; 2019. Available from: https://www. nuffieldtrust.org.uk/research/delivering-general-practice-withtoo-few-gps (accessed 5 June 2020). 